\title{
DEVELOPMENT OF A NEW URBAN LINE WITH INNOVATIVE TRAMS
}

\author{
FABIO BORGHETTI ${ }^{1}$, CRISTIAN GIOVANNI COLOMBO ${ }^{2}$, MICHELA LONGO $^{2}$, \\ RENATO MAZZONCINI ${ }^{3} \&$ CLAUDIO SOMASCHINI ${ }^{4}$ \\ ${ }^{1}$ Design Department, Mobility and Transport Laboratory, Politecnico di Milano, Italy \\ ${ }^{2}$ Department of Energy, Politecnico di Milano, Italy \\ ${ }^{3}$ A2A S.p.A., Italy \\ ${ }^{4}$ Department of Mechanical Engineering, Politecnico di Milano, Italy
}

\begin{abstract}
The trend of the population increase combined with the global climate change and the rising energy prices make sustainable mobility a big issue for urban communities. Since in urban areas it is in act a process of infrastructure development, the modernization of Light Rail Vehicle (LRV), whose final purpose is to intensify the urban transport network in an environmentally friendly way (reduction of visual and noise pollution), will be chased too. This paper is focused on a study developed in the North of Italy (Brescia) and its target is to plan a new tramline without catenary to reduce the urban and architectural impact of infrastructure. In this way, it is possible to reduce the environmental impact especially in specific areas of an urban centre. The work analyses the use of the batteries and the main parameters to size the storage system technology in order to supply the tram correctly whenever it crosses the catenary free section.
\end{abstract}

Keywords: mobility, tramway, light rail vehicles, APS, batteries, environmental sustainability, urban area, transportation planning, collective transport, public transport.

\section{INTRODUCTION}

Transport is a key sector of the economy: this sector comprises a complex network of 1.2 million private and public companies in the EU, employing 10.5 million people and providing goods and services to citizens and businesses. Today, there are a number of challenges facing the transport sector in the EU including, for example, creating a wellfunctioning Single European Transport Area, connecting Europe with modern, multimodal and safe transport infrastructure networks, and moving towards low-emission mobility, which also involves reducing other negative externalities of transport. The last issue of sustainable mobility, especially in urban areas, plays a key role in the decision-making process of transport system planning. Nowadays about the $55 \%$ of global population lives in urban areas and this percentage is destined to increase up to $68 \%$ by 2050 , making it necessary to develop new mobility systems. Indeed, cities are places where large numbers of people live and work; they are centres of government, commerce, and transportation [1].

Regarding the modal split in Italy in the year 2018 it is observed that the use of the car represents a high value over $82 \%$. Fig. 1 shows the modal split for motor coaches, buses and trolley buses; passengers' cars and trains in the period 2014-2018 [2].

Electric mobility can play an important role in the pursuit of this goal following the standards established by the European Commission in Brussels [3]. The aim of mobility in the future is to satisfy the transport demand and to cooperate with different modes of transport system following the goals of effectiveness, efficiency and quality able to provide a socio-economic sustainability, respecting an environment without neglecting safety [4], [5]. Following the mobility trends and considering the general macrotrends, such as the growth of people who lives in urban areas, this work wants to improve a mobility system 


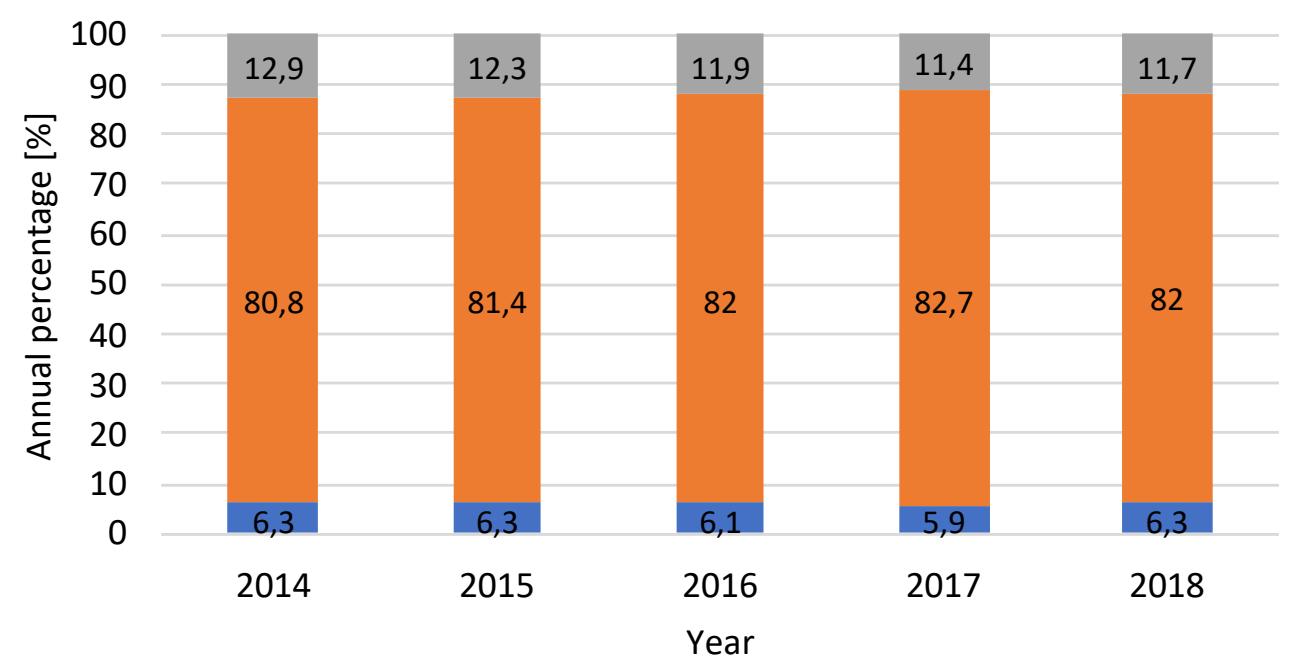

Trains $\square$ Passengercars $\square$ Motor coaches, buses and trolley buses

Figure 1: Modal split for passenger transport in Italy in the period 2014-2018.

with the implementation of a tramway line with innovative solutions, in order to give an answer to the queries mentioned. In this way, to increase the efficiency and the safety, it is necessary to intensify the interoperability between different collective transports, both with the optimization of the tables routes and the use of a communication system between trams. This second point could be resolved through the utilization of SCADA (Supervisory Control and Data Acquisition) and a traffic light priority system, able to communicate continuously between the vehicle and the infrastructure (route) [6]-[8]. This optimization is respected also by the line feeding, in fact, using a third rail alimentation during the route, only a small section will be powered (few meters more than the trams) assuring the safety. This leads to the necessity of an efficient system of communication between the control room and the tram. Moreover, the use of the third rail or batteries allows to avoid the visual pollution created by the catenary, that can result unpleasant in the specific area of the city [9]-[11]. Finally, it is important to reduce noise and in this way new tram with innovative Heating, Ventilation and Air Conditioning (HVAC) system is developed [12]. To deal with the absence of the infrastructure in the city centre, the advantages and the drawbacks of the main technologies must be considered. For batteries, the main advantages are the possibility to operate without catenary or wires for some kilometres; this allows to reduce the probability to have an electrical failure on the infrastructure, moreover the visual impact of the line feeding is avoided. But the drawbacks of this technology are linked to the increase of weight, which could become an issue with higher power requirements and the limited battery life, leading to potential high maintenance requirements [13], [14].

The third rail power supply allows catenary-free operations too, also for long distance and the maintenance become an easy task due to the possibility to access in case of fault and encumbrances, even in case of crossing are avoided and the infrastructure has a minimal visual impact. The drawbacks to face are mainly economics since the proprietary system would limit competition and operating maintenance cost may be significantly higher 
compared to other systems. Moreover, environmental conditions, like snow and ice, must be considered making costs certainly higher for the different situations. Finally, safety certifications may require additional work when compared to Electric Substations (ESS) based systems [15]. The goal of this paper, after the presentation of the modern technologies to reduce the visual impact of the tramway infrastructure, is the application of one of the solutions proposed, the storage system one (Fig. 2). This paper is focused on a study developed in the North of Italy and its target is to plan a new tramline without catenary to reduce the urban and architectural impact of line feeding. The work analyses the use of the batteries and the main parameters to size the storage system technology in order to supply the tram correctly whenever it crosses the catenary free section.

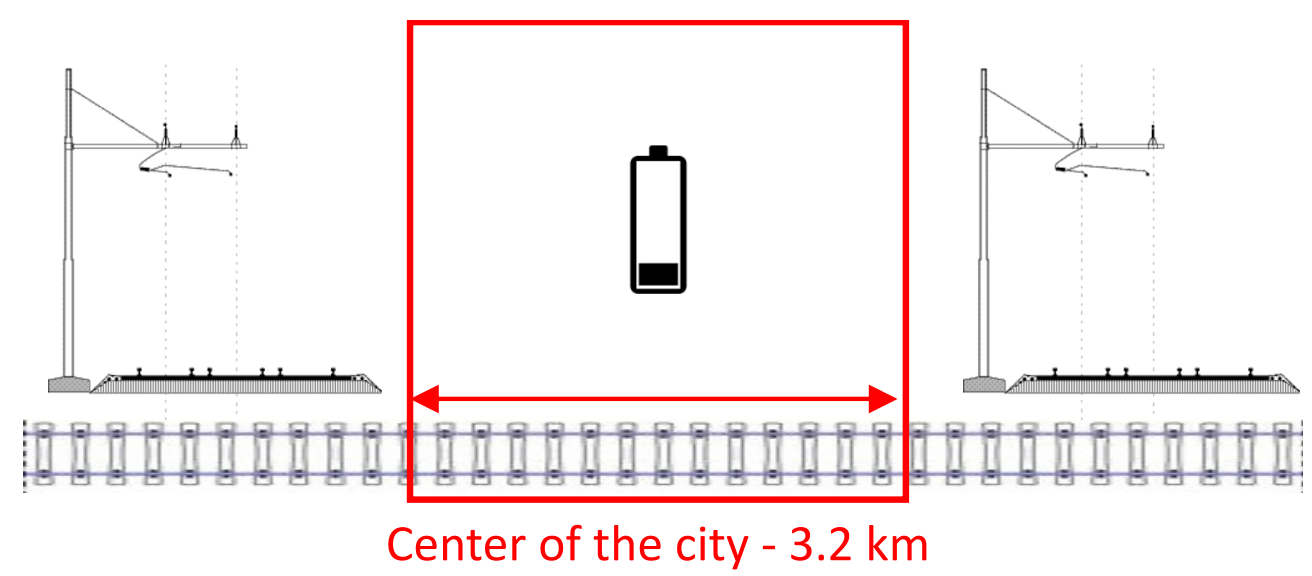

Figure 2: Representation of the aim of the paper: analysis and dimensioning of a battery system of a tramway to cross the city centre.

\section{NOMENCLATURE}

$F_{T, A D}:$ Adhesion force;

$f_{A D}$ : Adhesion coefficient;

$m$ : Mass of vehicle;

$m_{e}$ : Equivalent mass;

$N_{\text {motorized boogies }}$ : Number of motorized boogies;

$N_{\text {total boogies }}$ : Number of total boogies;

$F_{T \max }$ : Maximum tractive effort;

$F_{T}$ : Tractive effort;

$v_{b}$ : Base speed;

$P_{\text {max }}:$ Maximum power;

$R_{0}$ : Rolling resistance and aerodynamic resistance;

$R_{i}$ : Grade resistance;

$i$ : Slope;

$R_{c}$ : Curvature resistance;

$\rho$ : Curvature radius;

$v_{n}:$ Speed at time instant $n$

$v_{n+1}$ : Speed at time instant $n+1$, subsequent to $n$; 
$a_{n}:$ acceleration at time instant $n$;

$t_{n}:$ time at instant $n$

$t_{n+1}$ : time at instant $n+1$, subsequent to $n$;

$P_{T \mathrm{r}}$ : Power in phase of traction;

$\eta_{\mathrm{T}}$ : Efficiency in phase of traction;

$P_{A U X}$ : Auxiliary power;

$P_{B r}$ : Power in phase of braking;

$\eta_{\mathrm{B}}$ : Efficiency in phase of braking;

$e_{b r}$ : regenerative percentage of recovery braking;

$E_{n}$ : Energy at time instant $n$;

$E_{n+1}$ : Energy at time instant $n+1$, subsequent to $n$;

SoC: State of charge;

DoD: Depth of discharge.

\section{FOCUS ON THE CASE STUDY IN NORTH ITALY}

In this section, the focus is on analyzing and evaluating the application of new technology to achieve mobility goals, evaluating the construction of a new tramway system in Northern Italy (Brescia). The total length considered is articulated for $22 \mathrm{~km}$ divided in three lines into the city as reported in Fig. 3 with red line.

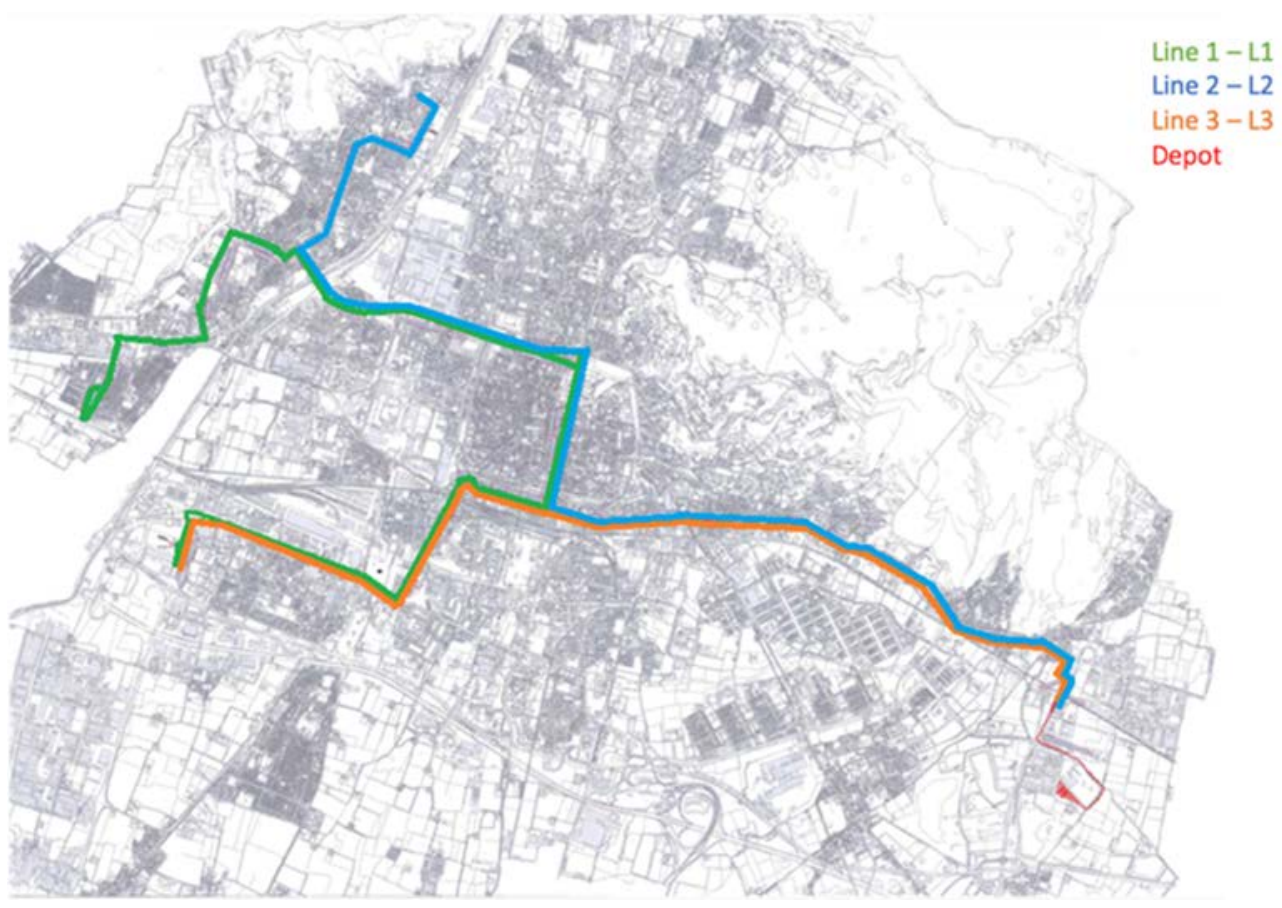

Figure 3: Representation of the three tram lines (L1, L2 and L3) in the city located in North Italy. (Source: The authors.)

The main issue of this project is to solve the problem of crossing the centre of the city without using the catenary to reduce the visual impact and the cost of the infrastructure. 
The longest catenary free section is $3.2 \mathrm{~km}$ long over a line length of about $13.5 \mathrm{~km}$. The focus is concentrated on the tramline 2 (L2) which contains this section. Moreover, it must be considered that the tram does not stop for a long time at the terminals, so a roundtrip represents a single journey. Finally, focusing on this line, it is possible to evaluate the different diagrams to size the battery.

The total amount of tram stops is 39 and the vehicles necessary to provide the service are 20.

Respecting the state of art of the infrastructure, in the city, it is needed to build a new one, implementing a bigger power grid. In this way 13 new Electric Substations (ESS), with a maximum power of $900 \mathrm{~kW}$, to supply the contact line are considered. According to state of art infrastructure and simulations, the overhead line must present these characteristics:

- Cable section: $150 \mathrm{~mm}^{2}$ with $20 \%$ wear;

- Voltage: $750 \mathrm{~V}_{\mathrm{DC}}$;

- Maximum current: 480 A;

- Height: $5.5 \mathrm{~m}$.

The rail infrastructure is dimensioned respecting the normal issues: a gauge of $1,435 \mathrm{~mm}$ and a resistance related to the running rail contact of $20 \mathrm{~m} \Omega / \mathrm{m}$. Every $500 \mathrm{~m}$, one-line feeder is connected along the line, while the negative equipotential is placed every $150 \mathrm{~m}$. Moreover, it can be considered some data about the third rail if it will be necessary to install it. The data are similar using Alimentation Par le Sol (APS), with the difference that the maximum current will be a little bit less $(470 \mathrm{~A})$. The vehicle selected for this study is the Citadis X05 class (Fig. 4) that belongs to the fleet of vehicles developed by Alstom. Therefore, considering the features required by the path (L2) the chosen one is Citadis 305 light. The light model is selected because it is necessary to cross some section too narrow for the normal one.

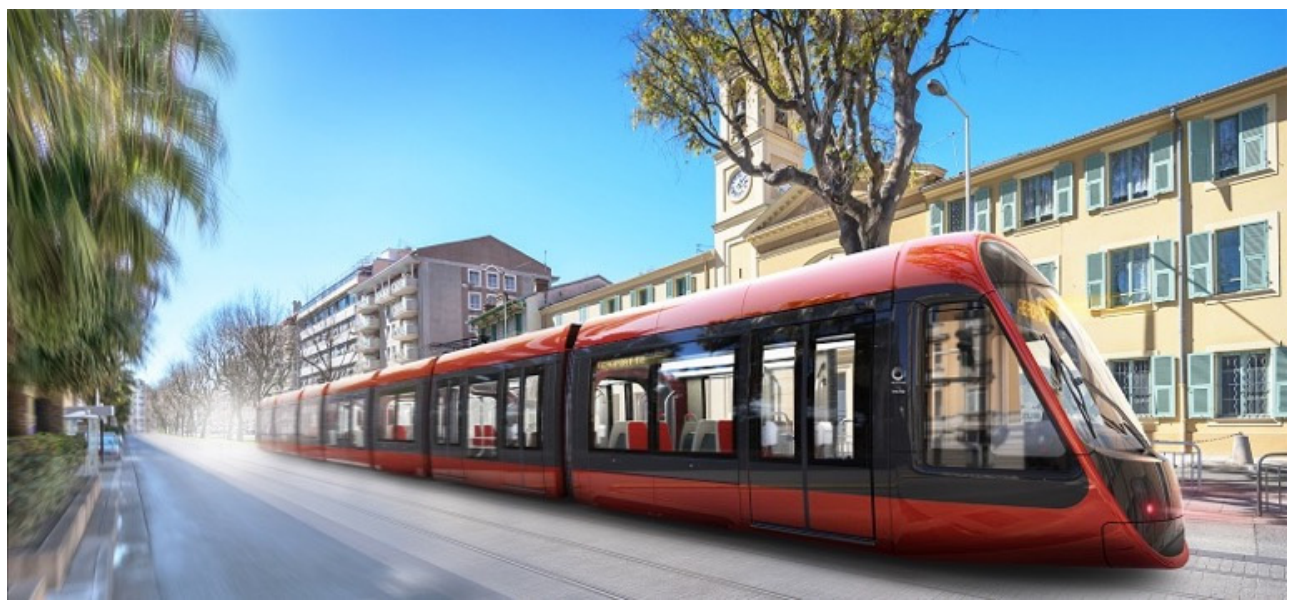

Figure 4: Citadis X05 Class Tram [16]. 


\section{SIMULATIONS AND DISCUSSION OF RESULTS}

In this section, the tram line (L2) is simulated considering the maximum speed possible taking into account the limits, providing the worst case of energy and power demand, and adhesion control, in order to be as sure as possible to satisfy the requirements.

\subsection{Traction diagram and adhesion control}

The traction diagram is the representation of the traction force applied by the engines on the rails, as a function of the speed of the vehicle. At the same time, it is also necessary to check that the adhesion force is higher enough to avoid slippage phenomena. This value depends on the wheelset arrangement and on the ratio between the motorized bogies ( $\left.N_{\text {motorized boogies }}\right)$ and the total number of bogies $\left(N_{\text {total bogies }}\right)$ of the vehicle. Based on the vehicle chosen there are two motorized boogies for a total number of three. It is possible to use a specific coefficient, which compose the adhesion coefficient $\left(f_{A D}\right), f_{0}=0.25$ (worst case, wet conditions), to have an adhesion force $\left(F_{T, A D}\right)$ like in eqn (1):

$$
F_{T, A D}[\mathrm{kN}]=f_{A D} \cdot m \cdot g \cdot \frac{N_{\text {motorized bogies }}}{N_{\text {total bogies }}}=f_{0} \cdot m \cdot 9.81 \cdot \frac{N_{\text {motorized bogies }}}{N_{\text {total bogies }}} .
$$

The maximum starting tractive effort $\left(F_{T \max }\right)$ of the vehicle, which equivalent mass is $m_{e}$, at the maximum acceleration $(a)$ is evaluated using eqn (2):

$$
F_{\text {Tmax }}[\mathrm{kN}]=m_{e} \cdot a \text {. }
$$

The maximum tractive force is applied until its base speed $\left(v_{b}\right)$ is reached, evaluated by the ratio between the maximum power $\left(P_{\max }\right)$ and the maximum tractive effort $\left(F_{T \max }\right)$, as shown in eqn (3):

$$
v_{b}\left[\frac{\mathrm{m}}{\mathrm{s}}\right]=\frac{P_{\max }}{F_{T \max }} .
$$

At this point, it is not possible to exceed the maximum traction power that can be supplied by the motor, so from the constant torque region it is possible to move to the constant power region, where the traction force decreases and is calculated by the following eqn (4):

$$
F_{T}[\mathrm{kN}]=\frac{P_{\max }}{v}
$$

Finally, during the braking phase the traction force is evaluated using eqn (2), but the braking acceleration $\left(a_{b r}\right)$ is required instead of the starting acceleration $(a)$.

Following these criteria, the traction force is simulated and provide the result shown in Fig. 5 , where the blue line is the tractive effort during the catenary traction, while the red one represents the battery traction mode.

In according to the equations, Fig. 6 shows the adhesion control, for Line 2, where in blue is highlighted the traction force and in red the adhesion force, in phase on traction (the red line in the upper part of the figure) and in phase of braking (the red line in the lower part of the figure). 


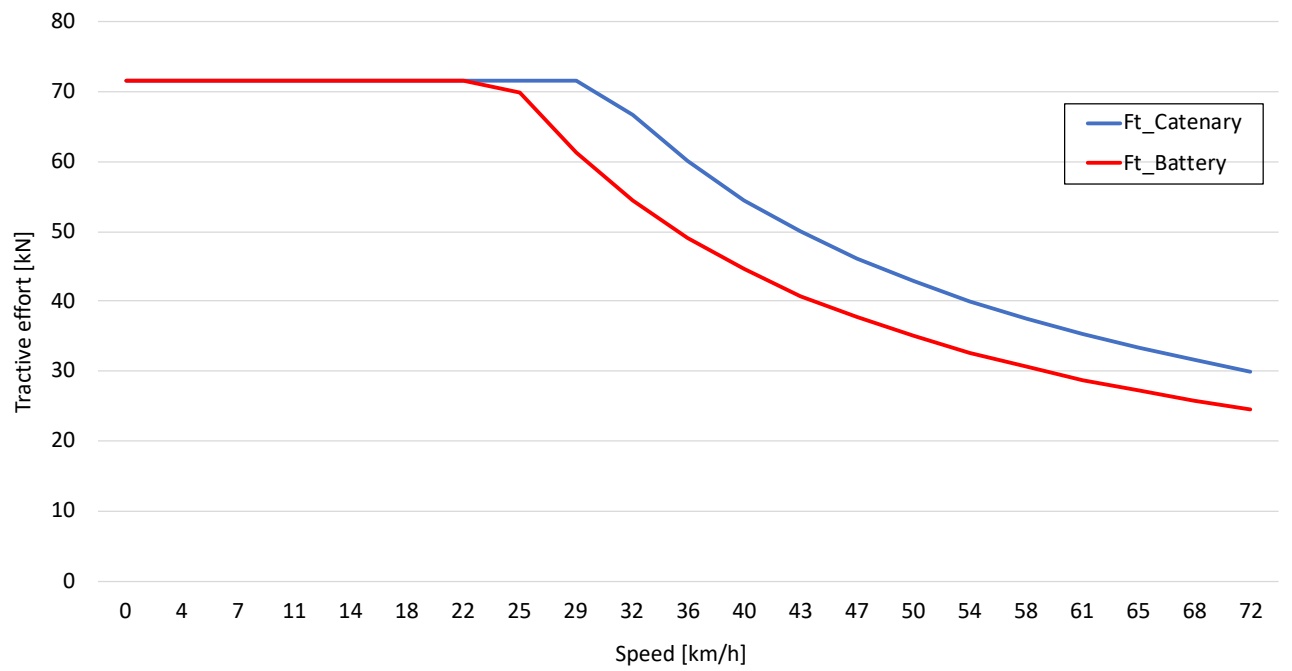

Figure 5: Traction force diagrams, blue in catenary mode and red in battery mode.

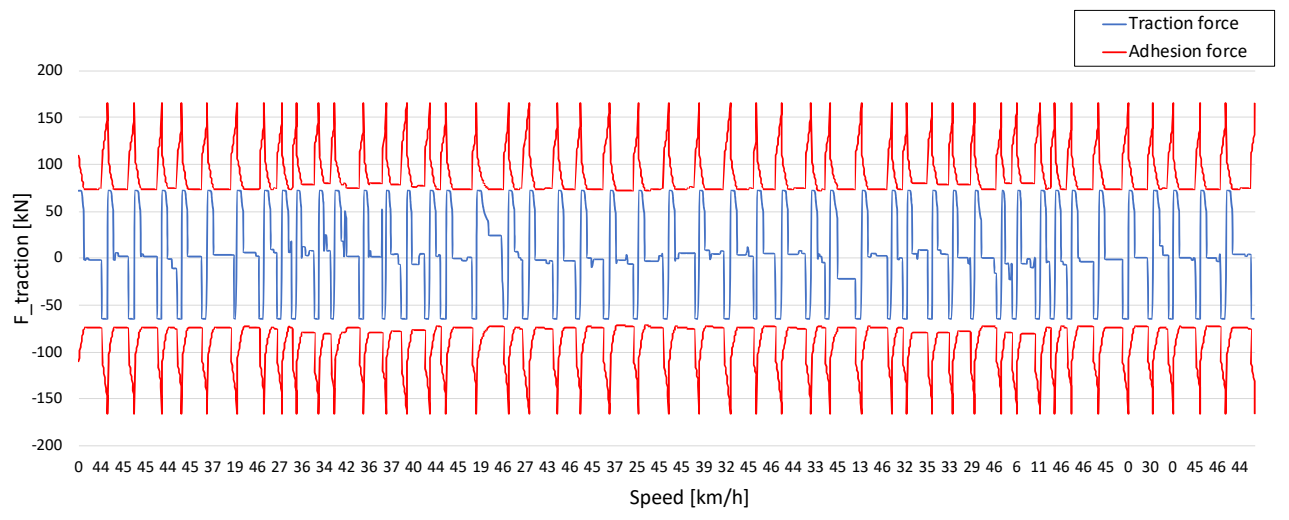

Figure 6: Adhesion control, Line 2.

\subsection{Speed diagram}

As the tram's speed increases, it is necessary to evaluate all the resistances included in the resultant of passive forces $R$ to evaluate the speed and space profile diagrams. There are four resistances to consider:

- Rolling resistance related to the deformation of the wheel in contact with the rail, and the aerodynamic resistance, linked to the vehicle motion through air, are evaluated by eqn (5), where the speed $v$ is considered in $\mathrm{km} / \mathrm{h}$ :

$$
R_{0}[\mathrm{kN}]=\left(1.4+0.018 \cdot\left(\frac{v}{10}\right)^{2}\right) \cdot m \cdot g .
$$


- Grade resistance $\left(R_{i}\right)$ related to the slope of the ground (i, evaluated in \%o) and the additional component of the tram's weight force which can be projected along the surface direction, evaluated in eqn (6):

$$
R_{i}[k N]=m \cdot g \cdot i .
$$

- Curvature resistance $\left(R_{c}\right)$ related to the different tangential speeds of the internal and external wheels of a single wheelset, described by eqn (7) where $\rho$ is the curvature radius in $m$ :

$$
R_{c}[\mathrm{kN}]=\frac{0.8}{\rho} \cdot m \cdot g .
$$

Speed profile diagram is evaluated computing all the resistances according to the route characteristics, applying the traction force according to the tram operating mode, computing the acceleration from Newton's law, evaluating speed through the discrete integration reported in eqn (8):

$$
v_{n+1}[\mathrm{~m} / \mathrm{s}]=a_{n} \cdot\left(t_{n+1}-t_{n}\right)+v_{n}
$$

During the journey, there are some speed limitations related to the presence of the curves and traffic lights; in order to guarantee a continuous adhesion between the rail and the wheel and to prevent accident, the speed is decreased. Once the speed limitation has been exceeded, the traction force is reapplied, and the speed will increase again. In Fig. 7, it is possible to see the speed limitation linked to the use of the battery traction to cross the city centre.

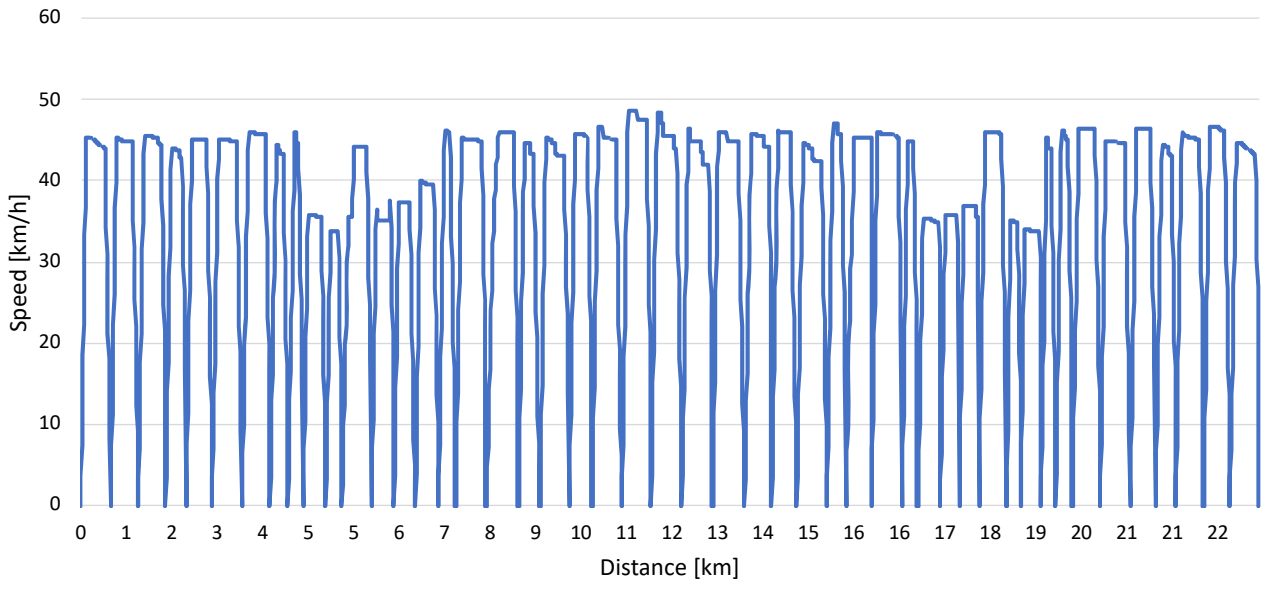

Figure 7: Speed diagram, Line 2.

\subsection{Power and energy diagram}

In this section, power and energy diagrams are evaluated. For the purposes of the calculations, the efficiency $(\eta)$ is evaluated not too differently depending on the type of 
traction. The regenerative percentage of recovery braking $\left(e_{b r}\right)$ has been assumed to be equal to $30 \%$. The powers related to the services must be guaranteed regardless of the speed at which the vehicle runs. The electric power taken from the catenary or the battery during the traction phase $\left(P_{T r}\right)$ is evaluating using eqn (9), while during the braking phase $\left(P_{B r}\right)$ is determined by eqn (10):

$$
\begin{gathered}
P_{T r}[\mathrm{~kW}]=\left(\frac{F_{T} \cdot v}{\eta_{T}}\right)+P_{A U X} . \\
P_{B r}[k W]=\left(F_{T} \cdot v \cdot \eta_{B}\right) \cdot \mathrm{e}_{\mathrm{br}}+P_{\mathrm{AUX}} .
\end{gathered}
$$

Finally, the energy diagram is evaluated through a discrete integration (11):

$$
E_{n}[\mathrm{kWh}]=\frac{P_{n}}{3,600} \cdot\left(t_{n}-t_{n-1}\right)+E_{n-1} .
$$

The energy required for operations constantly increases due both to the losses in the recovery braking and for the operation of auxiliary services. The slumps represented in Fig. 8 are linked to the subtraction of kinetic energy linked to the braking phases approaching a curve or a station. The roundtrip operation requires an amount of energy approximately of $133.16 \mathrm{kWh}$. To overcome the city centre, the distance is $3.2 \mathrm{~km}$ and the energy needed to travel this distance is about $16.4 \mathrm{kWh}$.

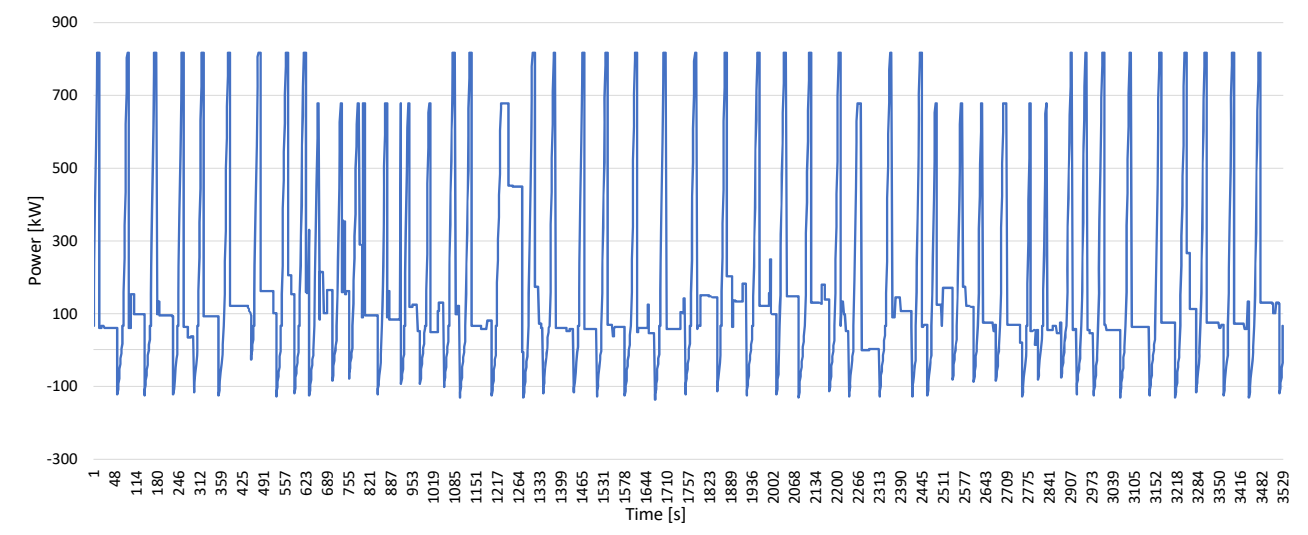

Figure 8: Power diagram, Line 2.

\subsection{Results of the simulation and sizing of the batteries}

The system is well dimensioned because the currents never reach dangerous values. The simulated lowest voltage is $670 \mathrm{~V}$ and the maximum power at the substations is below $900 \mathrm{~kW}$. Moreover, it could be possible to reduce the number of substations (ESS) from 13 to eight. The peak power reached in the worst case is about $800 \mathrm{~kW}$ and the power characteristic overcome the $400 \mathrm{~kW}$ for 72 seconds out of the 748 seconds where the catenary is not present, and the energy required to cover this section is $16.4 \mathrm{kWh}(3.2 \mathrm{~km})$. 
This lead to the possibility of installing only two branches of battery if the commercial speed is respected, since the peak power requirements is low. The ratio as indicated in eqn (12) allows to identify the main features that the battery must have on board:

$$
\frac{\text { Peak Power }}{\text { Energy }} \approx 42 \text {. }
$$

Therefore, in order to satisfy the peak power demand, batteries with a high-power density have to be chosen. So, the battery chosen is the LTO (lithium-titanate) which the main characteristics are reported in Table 1.

Table 1: Main characteristics of the batteries.

\begin{tabular}{|l|c|}
\hline Type of battery & LTO battery \\
\hline Number branches & 2 \\
\hline One battery capacity $(\mathrm{kWh})$ & 28 \\
\hline Tram battery capacity $(\mathrm{kWh})$ & 56 \\
\hline Maximum power battery $(\mathrm{kW})$ & 490 \\
\hline Constant charge/discharge rate $(\mathrm{C})$ & 3 \\
\hline Peak charge/discharge rate $(\mathrm{C})$ & 9 \\
\hline
\end{tabular}

This choice of the battery comes from these requirements:

- High security;

- High consistency;

- High rate;

- $\quad$ Long cycle life.

Lithium-titanate (LTO) battery is a type of lithium-ion battery with outstanding safety performance, high rate, and very long cycle life [17]. It has over $80 \%$ capacity only charging within several minutes and has a good over-discharging resistance and antireverse charging protection, so there is no safety issue of explosion or fire even if it has overcharged, charged reversely or short circuit accidently. Moreover, the good range of temperature is between $-35^{\circ}$ and $75^{\circ}$.

Fig. 9 highlights the state of charge (SoC) of the battery where the battery starts from a SoC of the $80 \%$ and arrive at a minimum of $50 \%$; the depth of discharge (DoD) is around $30 \%$. It is important to not discharge or recharge completely the battery to avoid a reduction of its lifetime. The lifetime of the battery depends on the depth of discharge patterns, a smaller DoD, in fact, extend the lifetime of the battery. The wear depends on DoD, but also on the recharging rate and the number of cycles per day, in fact a too fast recharge may degrades too much the battery and consequently decreases its lifetime.

\section{CONCLUSIONS}

The new challenge for the mobility sector is the respect of the environment around us. In this way, the companies are studying new several methods to supply the trams in the cities in order not only to decrease the environmental pollution and impact, but even increasing 


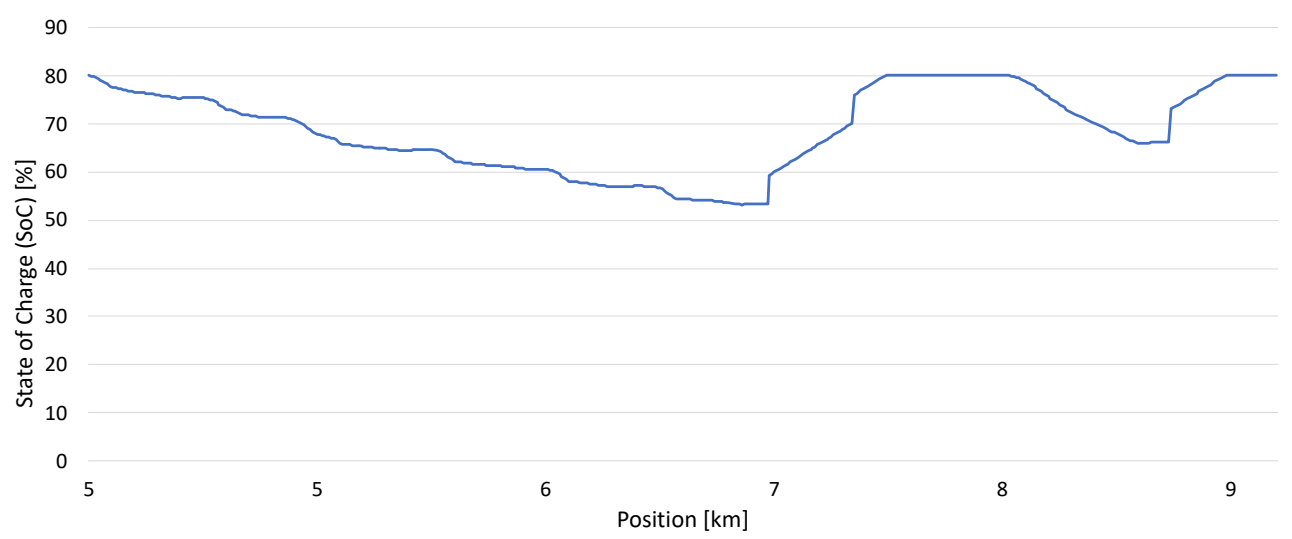

Figure 9: State of charge (SoC) of the battery during the catenary free sections, Line 2.

the capacity, the flexibility and the speed, making the passengers experience more comfortable. This paper is focused on a study developed in the north of Italy and its target is to plan a new tramline without catenary to reduce the urban and architectural impact of line feeding. The work analyses the use of the batteries and the main parameters to size the storage system technology in order to supply the tram correctly whenever it crosses the catenary free section ( $3.2 \mathrm{~km}$ long over a line long about $13.5 \mathrm{~km})$.

Many investments are needed to improve catenary-less solutions, in order to preserve the beauty of historical areas, or city centre: Alimentation Par le Sol (APS) and the batteries are two of them. In order to satisfy the peak power demand (about $800 \mathrm{~kW}$ ), batteries with a high-power density are chosen. In fact, the problem is not the total amount of energy but the high require of power. So, the battery chosen is the LTO (lithium-titanate). After the analyses and the evaluation of the mechanical aspects, the electrical one are considered, providing information useful to size the alternative supply system for the catenary free section. Therefore, the service evaluated is not only efficient but also environmentally friendly, in order to preserve the landscape of the areas in the city centre, avoiding the use of the overhead line encouraging the use of alternative power supplies such as APS and storage systems. The main limitation of the storage system technology is linked to the weight: in fact, the higher the number of battery is, the higher will be the load, therefore the tractive effort to move the tram will increase, and so the power required to the system. This became an issue for the lifetime of the battery, leading to an higher maintenance costs.

\section{REFERENCES}

[1] United Nations, Department of Economic and Social Affairs, Population Division, World urbanization prospects: The 2018 revision, 2018. https://population.un.org/ wup/Publications/Files/WUP2018-Report.pdf. Accessed on: 30 Apr. 2021.

[2] EUROSTAT 2021, Modal Split of Passenger Transport. https://ec.europa.eu/eurostat/ databrowser/view/t2020_rk310/default/table?lang=en. Accessed on: 30 Apr. 2021.

[3] European Commission, Ecosystem Services and Green Infrastructures, 2019. https://ec.europa.eu/environment/nature/ecosystems/index_en.htm. Accessed on: 30 Apr. 2021. 
[4] Barabino, B., Cabras, N.A., Conversano, C. \& Olivo, A., An integrated approach to select key quality indicators in transit services. Social Indicators Research, 149(3), pp. 1045-1080, 2020. DOI: 10.1007/s11205-020-02284-0.

[5] Barabino, B., Deiana, E. \& Tilocca, P., Urban transport management and customer perceived quality: A case study in the metropolitan area of Cagliari, Italy. Theoretical and Empirical Researches in Urban Management, 6(1), pp. 19-32, 2011.

[6] Zolotová, I. \& Landryová, L., SCADA/HMI systems and emerging technologies, IFAC proceedings, 33(1), pp. 17-20, 2000.

[7] Flochová, J. \& Hrúz, B., Supervisory control for discrete event dynamic systems based on petri nets. Proceedings of International Conference on Process Control, Horní Bečva, 2, pp. 80-83, 1996.

[8] Harčarufka, R. \& Harčarufková, K., New trends in electrical drives engineering education EDPE '99, Electrical Drives and Power Electronics, International Conference, Slovakia, pp. 148-151, 1999.

[9] Bartłomiejczyk, M. \& Połom, M., Possibilities for developing electromobility by using autonomously powered trolleybuses based on the example of Gdynia. Energies, 14(10), p. 2971, 2021.

[10] Bartłomiejczyk M. \& Połom M., Sustainable use of the catenary by trolleybuses with auxiliary power sources on the example of Gdynia. Infrastructures, 6(4), 61, 2021.

[11] Brenna, M. et al., A review on energy efficiency in three transportation sectors: Railways, electrical vehicles and marine. Energies, 13(9), 2020.

[12] Połom, M., Technology development and spatial diffusion of auxiliary power sources in trolleybuses in European countries. Energies, 14, p. 3040, 2021.

[13] Zhang, T., Ballantyne, E.E.F., Zhao, R. \& Stone, D.A., Technical and economic feasibility of increasing tram system efficiency with EV batteries. Transportation Research Part D: Transport and Environment, 91, 2021.

[14] Ahmadi, M., Kaleybar, H.J., Brenna, M., Castelli-Dezza, F. \& Carmeli, M.S., Adapting digital twin technology in electric railway power systems, 2021 12th Power Electronics, Drive Systems, and Technologies Conference, PEDSTC 2021, 2021.

[15] Marcin, W., Szmelter-Jarosz, A., Koniak, M. \& Golejewska, A., Transformation of trolleybus transport in Poland. Does in-motion charging (technology) matter? Sustainability, 12(22), 2020.

[16] ALSTOM. https://www.alstom.com/our-solutions/rolling-stock/citadis-rangereference-urban-and-suburban-transport. Accessed on: 30 Apr. 2021.

[17] Largepower, Custom lithium ion battery pack. http://www.lithiumionbatterypack.com/lithium-titanate-battery.html. Accessed on: 30 Apr. 2021. 